\title{
Comparison of Resident, Advanced Practice Clinician, and Hospitalist Teams in an Academic Medical Center: Association With Clinical Outcomes and Resource Utilization
}

\author{
Stacy A Johnson, MD ${ }^{1 *}$, Claire E Ciarkowski, MD ${ }^{1}$, Katie L Lappe, MD1,2, \\ David R Kendrick, PA-C ${ }^{1}$, Adrienne Smith, PA-C1', Santosh P Reddy, MD'
}

${ }^{1}$ Division of General Internal Medicine, Department of Internal Medicine, School of Medicine, University of Utah, Salt Lake City, Utah; ${ }^{2}$ Division of General Internal Medicine, Department of Internal Medicine, George E. Wahlen VA Hospital, Salt Lake City, Utah.

BACKGROUND: Academic medical centers have expanded their inpatient medicine services with advanced practice clinicians (APCs) or nonteaching hospitalists in response to patient volumes, residency work hour restrictions, and recently, COVID-19. Reports of clinical outcomes, cost, and resource utilization differ among inpatient team structures.

OBJECTIVE: Directly compare outcomes among resident, APC, and solo hospitalist inpatient general medicine teams.

DESIGN: Retrospective cohort study using multivariable analysis adjusted for time of admission, interhospital transfer, and comorbidities that compares clinical outcomes, cost, and resource utilization.

SUBJECTS: Patients 18 years or older discharged from an inpatient medicine service between July 2015 and July $2018(\mathrm{~N}=12,716)$.

MAIN MEASURES: Length of stay (LOS), 30-day readmission, inpatient mortality, normalized total direct cost, discharge time, and consultation utilization.
KEY RESULTS: Resident teams admitted fewer patients at night $(32.0 \% ; P<.001)$ than did APC $(49.5 \%)$ and hospitalist $(48.6 \%)$ teams. APCs received nearly $4 \%$ more outside transfer patients $(P=.015)$. Hospitalists discharged patients 26 minutes earlier than did residents (mean hours after midnight [ $95 \% \mathrm{Cl}], 14.58$ [14.44-14.72] vs 15.02 [14.97-15.08]). Adjusted consult utilization was $15 \%$ higher for APCs (adjusted mean consults per admission [95\% $\mathrm{Cl}], 1.00$ [0.96-1.03]) and $8 \%$ higher for residents $(0.93$ [0.90-0.95]) than it was for hospitalists $(0.85$ [0.80-0.90]). No differences in LOS, readmission, mortality, or cost were observed between the teams.

CONCLUSION: We observed similar costs, LOS, 30-day readmission, and mortality among hospitalist, APC, and resident teams. Our results suggest clinical outcomes are not significantly affected by team structure. The addition of APC or hospitalist teams represent safe and effective alternatives to traditional inpatient resident teams. Journal of Hospital Medicine 2020;15:709-715. () 2020 Society of Hospital Medicine

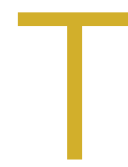

he Accreditation Council for Graduate Medical Education (ACGME) first mandated residency work hour restrictions in 2003. ${ }^{1}$ In 2011, revised work hour requirements were issued, further limiting the maximum duration of a shift and extending the duration of time off between scheduled shifts. ${ }^{2}$ Academic medical centers have been forced to adapt to work hour restrictions, and cuts in funding to research and educational missions have pressured institutions to restructure with a greater focus on high-quality, lower-cost care. ${ }^{3,4}$ In response, many academic hospitals have added hospitalist teams, or incorporated advanced practice clinicians (APCs) (nurse practitioners [NPs] and physician assistants [PAs]) to accommodate resident physician duty hour restrictions on their inpatient general medicine services. ${ }^{5,6}$ More

*Corresponding Author: Stacy A Johnson, MD; Email: stacy.a.johnson@ hsc.utah.edu; Telephone: 801-581-7822.

Published online first November 18, 2020

Received: March 12, 2020; Revised: May 12, 2020; Accepted: May 20, 2020

๑ 2020 Society of Hospital Medicine DOI 10.12788/jhm.3475 recently, the COVID-19 pandemic has created unanticipated physician shortages forcing medical centers to rapidly expand and broaden the scope of their existing APC workforce.?

Several comparisons of clinical outcomes, cost, and patient satisfaction between different combinations of hospitalist-based, resident-based, or APC-based inpatient teams have been reported with conflicting observations. ${ }^{6,8-14}$ Roy et al reported no significant differences in mortality, length of stay (LOS), or readmissions between PA and resident teams. ${ }^{6}$ Timmermans et al reported similar cost-effectiveness, LOS, and quality of care between PA and physician teams that included a hybrid of attending only and resident teams. ${ }^{13,14}$ Alternatively, Singh et al and lannuzzi et al reported increased LOS among PA teams, ${ }^{10,12}$ whereas Chin et al observed an increased LOS and reduced 30-day readmissions among hospitalist teams. ${ }^{8}$ While these observed differences may be attributable to heterogeneous patient populations or institution-specific team structure, the exact reasons remain unknown. Furthermore, understanding the value of alternate staffing models is essential for medical centers to prepare for potential COVID-19 related physician shortages. To our knowledge, no study to date 
has directly compared outcomes between resident, APC, and hospitalist team structures within an academic medical center.

We believe our institution provides a unique environment to study the differences in inpatient general medicine team structure with respect to quality and efficiency of care delivery. The objective of our study is to directly compare clinical outcomes and resource utilization among three distinct team structures: APC, resident, and solo hospitalist. We hypothesize that clinical outcomes, cost, and utilization of consult services will be similar across all team structures and hospitalist teams will discharge patients earlier than resident and APC teams.

\section{METHODS}

\section{Study Design and Setting}

We conducted a retrospective observational cohort study at the University of Utah Medical Center, a 548-bed academic medical center in Salt Lake City. An electronic database query was used to identify all patients discharged from the inpatient general internal medicine service between July 1, 2015, and July 1, 2018. Baseline patient characteristics were collected including age, gender, and Charlson comorbidity index $(\mathrm{CCl}) .{ }^{15}$ Case-mix index was determined for admissions where a Medicare Severity Diagnosis Related Group (MS-DRG) and corresponding weight was assigned. ${ }^{16,17}$ Source of admission was collected to identify patients transferred from an outside hospital, typically due to increased medical complexity or need for specialty care not available at the referring center. Time of admission was collected to classify whether a patient was admitted during the day or at night. Length of stay was calculated as the difference between discharge date/time and admission date/time. Discharge order time was collected as a measure of clinician efficiency. The number of consults per admission was determined by the number of different medical or surgical subspecialty services that wrote at least one consultation or progress note after the time of admission and were not the primary service at the time the note was written. The project was reviewed and deemed exempt by the University of Utah Institutional Review Board (IRB 00104884).

\section{Inpatient Care Team Structure}

Patients were assigned to one of three cohorts dependent on the assigned treatment team at the time of discharge. The three inpatient team structures were as follows: (1) a "resident team" composed of a senior resident (postgraduate year [PGY] 2 or PGY3) and one to two medical students or one senior resident, two interns (PGY1), and one to two medical students supervised by a hospitalist physician; (2) an "APC team" composed of one to two APCs supervised by a hospitalist physician; and (3) a "hospitalist team" composed of one attending hospitalist independently managing all patients.

\section{Advanced Practice Clinicians}

The APC service included 10 APCs (8 PAs and 2 NPs), with a combined workforce of nine APC full-time equivalents during the study period. Their experience ranged from new graduate to 11 years of clinical experience, with an average of 4.2 years.
Among the 6 APCs with prior clinical experience, the majority (86\%) of their years of clinical experience were within inpatient medicine, oncology, or cardiology. Recognizing the variability in clinical experience, we employed a rigorous onboarding program that entailed an average of 80 hours of didactic sessions including 1:1 teaching of the inpatient Society of Hospital Medicine core lecture series combined with initial intense clinical oversight. ${ }^{18}$ This program ranged from 2 weeks to 6 weeks depending on the individual APC's clinical experience, progress, and comfort working independently. This onboarding program has subsequently been formalized into a 1-year APC fellowship that began after the study period concluded.

The degree of autonomy for each APC was individualized based on their clinical experience and ability to recognize limitations such as medical decision-making, clinical knowledge, and effective use of interprofessional team members (eg, peers, nursing, ancillary staff, consultants, and support personnel). Those APCs who demonstrated a sufficient level of clinical competence functioned with a high level of autonomy. During the day, APCs were expected to be the first point of contact for interprofessional team members, to respond to acute clinical changes in a patient's condition, and to discuss active issues with the supervising attending, all with the majority of medical decision-making, direct patient communication, documentation, and care coordination performed by the APC. An experienced subset of the APC service was responsible for overnight coverage. Nocturnist APCs independently managed all cross-cover issues on patients assigned to APC and hospitalist teams and performed admissions with very little to no direct supervision of the overnight attending physician.

\section{Patient Admission and Redistribution Process}

During the study period, resident teams performed all daytime admissions (6 AM to 6 PM) on a rotating basis. On any given day, three of four resident teams performed daytime admissions with the fourth team designated as "golden" and free from admitting duties. Patients admitted during the day remained assigned to the resident team for continuity. The APC and hospitalist teams did not accept new admissions during the day. Nighttime admissions (6 PM to 6 AM) were performed by a separate team composed of two senior residents, two interns, one APC, occasional APC and medical students, and one supervising attending hospitalist. This team functioned as a single unit. Nighttime admissions were performed in a sequential and rotating fashion (eg, Intern $A>$ Intern $B>$ Resident $A>$ Resident $B>A P C>$ student(s) $>$ Intern $A>$ Intern $B$, etc). $\mathrm{Pa}$ tients admitted overnight were randomly redistributed the following morning, with the majority reassigned to an APC team or hospitalist team in order to offset the workload of the resident teams performing daytime admissions. Following redistribution, a patient would remain assigned to the daytime APC or hospitalist team for the duration of their hospitalization. The redistribution decisions were based on individual team census, without systematic consideration of an individual patient's diagnosis, medical complexity, socioeconomic status, or perceived quality of learning potential (eg, good teaching case). 


\section{Study Outcomes}

We divided study outcomes into two categories, clinical outcomes and resource utilization. Clinical outcomes included LOS, unplanned readmission within 30-days, and inpatient mortality and were designed to measure patient-related outcomes as a reflection of the quality of care delivered by different team structures. Resource utilization included discharge order time, discharge time, consults per admission, and total direct cost, which were designed to measure provider-related differences in efficiency and cost of care.

\section{Statistical analysis}

Baseline characteristics and unadjusted outcomes are reported as frequency and percent, normally distributed variables as mean with SD, and nonnormally distributed variables as median with interquartile range (IQR). Baseline characteristics and unadjusted outcomes were compared using the chi-square test or the $t$ test, where appropriate. Multivariable regression analysis using generalized linear models with a log link function and gamma distribution was used for continuous outcomes. Multivariable logistic regression was used for binary outcomes. ${ }^{10}$ Covariates included in regression models were age, gender, $\mathrm{CCl}$, transfer from an outside hospital, and nighttime admission. In a sensitivity analysis, we included MS-DRG weight as a covariate for $85 \%$ of hospitalizations in our cohort exclusive of observation stays, and our findings were qualitatively similar (data not reported but available on request). Adjusted continuous outcomes were estimated using marginal effects at the means. ${ }^{19}$ Due to the sensitivity of cost data and an institutional policy against disclosing cost figures, total direct costs were normalized using the unadjusted median and adjusted mean total direct cost of an admission to an APC team as the normalizing value. A $P$ value cutoff of .05 was used to determine statistical significance. Stata/IC version 16.1 (StataCorp) was used for all analyses.

\section{RESULTS}

Study Population

A total of 12,716 hospital admissions were identified during the study period. Of these, 7,943 (62.5\%) admissions were assigned to a resident team, 3,519 (27.7\%) admissions were assigned to an APC team, and the remaining 1,254 (9.9\%) were assigned to a hospitalist team. Baseline patient characteristics are reported in Table 1. Patients admitted to resident teams (mean age [SD], 56.9 [19.1] years) were younger than those admitted to an APC team (58.0 [19.3] years; $P=.004$ ) or a hospitalist team (58.2 [19.3] years; $P=.026$ ). The case-mix index (mean MS-DRG weight [SD], 1.44 [0.87]) was slightly lower for resident teams than that for APC teams (1.49 [0.90]; $P=.025$ ). Resident teams had a significantly lower proportion of night admissions than did APC teams (32.0\% vs $49.5 \% ; P<.001)$ and hospitalist teams (48.6\%; $P<.001$ ). APC teams were assigned more patients transferred from an outside hospital (19.1\%), compared with resident teams $(15.0 \% ; P<.001)$ and hospitalist teams (16.0\%; $P=.015)$. No other significant differences were observed in baseline characteristics between cohorts.

\section{Clinical Outcomes}

Unadjusted analysis demonstrated the LOS was similar among resident, APC, and hospitalist teams with a median (IQR) LOS of $2.90(1.86,4.26)$ days, $2.93(1.89,4.66)$ days, and $2.86(1.84$, 4.67) days, respectively. No significant differences were observed in unadjusted 30-day readmissions or inpatient mortality among the team structures (Table 2). Following multivariable adjustment for differences in baseline characteristics, no significant differences were observed in LOS, 30-day readmission, or inpatient mortality among teams (Table 3).

\section{Resource Utilization}

In unadjusted comparisons, hospitalist teams were observed to place discharge orders more than 30 minutes earlier than APC teams (median hours after midnight [IOR], 11.20 [9.63, 13.60] vs 11.73 [10.00, 13.87]; $P<.001)$ and 54 minutes earlier than resident teams $(12.10[10.38,13.90] ; P<.001)$ (Table 2). Consistent with the earlier placement of discharge orders, hospitalist patients were also discharged from the hospital 26 and 32 minutes earlier than APC and resident patients, respectively. APC teams also discharged patients slightly earlier $(6 \mathrm{~min}$ utes) than resident teams (median hours after midnight [IQR], $14.97[13.23,16.72]$ vs $15.07[13.42,16.73] ; P=.045)$. Median consultation use among teams was similar, although statistically significant differences were present. Normalized total direct cost was $8 \%$ higher $(P<.001)$ for admissions to APC teams than that for resident teams and $7 \%$ higher $(P=.008)$ than that for hospitalist teams in unadjusted analysis (Table 2).

Following multivariable adjustment, the mean differences in discharge order time and discharge time remained significant with hospitalist teams discharging patients an average of 20 to 30 minutes earlier than APC and resident teams (Table 3). Consultant utilization remained significantly different between teams, with APC teams utilizing consultants on average 15\% more than hospitalist teams $(P<.001)$ and $7 \%$ more than resident teams $(P=.001)$. The differences in total direct costs were not significant after adjusted analysis.

\section{DISCUSSION}

Many academic medical centers have expanded their workforce with APC or nonteaching hospitalist teams to accommodate the increasing volume of hospital admissions, resident work hour restrictions, ${ }^{1,2}$ and medical complexity of an aging population. Several hospitals have reported comparative outcomes between different care delivery models, with conflicting results., 6,10-12 In our study, we directly evaluated three inpatient care delivery models and found that hospitalist teams discharged patients more efficiently and utilized fewer consultants, compared with APC and resident teams. In spite of this improved efficiency, no significant differences were observed in cost or other clinical outcomes.

Our findings are important and further strengthen the evidence supporting the use of APCs on inpatient general medicine services and are of particular interest to academic centers struggling to expand staffing in order to offset the growth in patient volume and reduction in resident workforce. We be- 
TABLE 1. Baseline Patient Characteristics

\begin{tabular}{|c|c|c|c|c|c|c|}
\hline & $\begin{array}{l}\text { Resident team } \\
(\mathrm{N}=7,943)\end{array}$ & $\begin{array}{l}\text { APC team } \\
(\mathrm{N}=3,519)\end{array}$ & $\begin{array}{l}\text { Hospitalist team } \\
\quad(\mathrm{N}=1,254)\end{array}$ & $\begin{array}{c}P \text { value }^{\mathrm{a}} \\
\text { (Resident vs APC) }\end{array}$ & $\begin{array}{c}P \text { value } \\
\text { (APC vs hospitalist) }\end{array}$ & $\begin{array}{c}P \text { value }^{\mathrm{a}} \\
\text { (Resident vs hospitalist) }\end{array}$ \\
\hline $\begin{array}{l}\text { Age in years, } \\
\text { mean (SD) }\end{array}$ & $56.9(19.1)$ & $58.0(19.3)$ & $58.2(19.3)$ & .004 & .770 & .026 \\
\hline Female, №. (\%) & $3,943(49.6)$ & $1,808(51.4)$ & $610(48.6)$ & .086 & .096 & .512 \\
\hline $\begin{array}{l}\text { Case-mix index, } \\
\text { mean }(S D)^{b}\end{array}$ & $1.44(0.87)$ & $1.49(0.90)$ & $1.48(0.95)$ & .025 & .894 & .186 \\
\hline $\begin{array}{l}\text { Charlson Comorbidity Index, } \\
\text { median (IQR) }\end{array}$ & $3(1-6)$ & $3(1-6)$ & $3(1-6)$ & .864 & .486 & .393 \\
\hline \multicolumn{7}{|l|}{$\begin{array}{l}\text { Charlson Comorbidity Index, } \\
\text { No. (\%) }\end{array}$} \\
\hline $\mathrm{CCl} \leq 1$ & $2,562(32.3)$ & $1,117(31.7)$ & $426(34)$ & .587 & .147 & .228 \\
\hline $\mathrm{CCl} 2-3$ & $1,865(23.5)$ & $854(24.3)$ & $286(22.8)$ & .360 & .297 & .601 \\
\hline $\mathrm{CCl} 4-5$ & $1,364(17.2)$ & $606(17.2)$ & 206 (16.4) & .949 & .521 & .515 \\
\hline $\mathrm{CCl} 6-7$ & $1,003(12.6)$ & $441(12.5)$ & $154(12.3)$ & .887 & .817 & .731 \\
\hline $\mathrm{CCl} \geq 8$ & $1,149(14.5)$ & $501(14.2)$ & $182(14.5)$ & .748 & .810 & .964 \\
\hline $\begin{array}{l}\text { Transfer from Outside Hospital, } \\
\text { No. (\%) }\end{array}$ & $1,193(15)$ & $673(19.1)$ & $201(16)$ & $<.001$ & .015 & .354 \\
\hline Night Admission, No. (\%) & $2,545(32)$ & $1,743(49.5)$ & $610(48.6)$ & $<.001$ & .590 & $<.001$ \\
\hline \multirow[t]{10}{*}{$\begin{array}{l}10 \text { Most Frequent } \\
\text { MS-DRG Diagnoses, No. (\%)c }\end{array}$} & $\begin{array}{c}\text { Septicemia or severe } \\
\text { sepsis without mechanical } \\
\text { ventilation, 1,186 (17.8) }\end{array}$ & $\begin{array}{l}\text { Septicemia or severe } \\
\text { sepsis without mechanical } \\
\text { ventilation, } 587 \text { (19.0) }\end{array}$ & $\begin{array}{l}\text { Septicemia or severe } \\
\text { sepsis without mechanical } \\
\text { ventilation, } 177 \text { (16.7) }\end{array}$ & & & \\
\hline & $\begin{array}{l}\text { Disorders of nutrition, } \\
\text { metabolism, and fluid and } \\
\text { electrolytes, } 243 \text { (3.6) }\end{array}$ & $\begin{array}{l}\text { Infectious and parasitic } \\
\text { diseases with } \mathrm{OR} \\
\text { procedure, } 86(2.8)\end{array}$ & Renal failure, 46 (4.4) & & & \\
\hline & $\begin{array}{c}\text { Gastrointestinal } \\
\text { hemorrhage, } 153(2.3)\end{array}$ & $\begin{array}{l}\text { Pulmonary edema and } \\
\text { respiratory failure, } 66(2.1)\end{array}$ & $\begin{array}{c}\text { Gastrointestinal } \\
\text { hemorrhage, } 27 \text { (2.6) }\end{array}$ & & & \\
\hline & Renal failure, 141 (2.1) & $\begin{array}{c}\text { Gastrointestinal } \\
\text { hemorrhage, } 64 \text { (2.1) }\end{array}$ & $\begin{array}{l}\text { Alcohol/drug abuse or } \\
\text { dependence, } 25 \text { (2.4) }\end{array}$ & & & \\
\hline & $\begin{array}{l}\text { Pulmonary edema } \\
\text { and respiratory failure, } \\
138(1.7)\end{array}$ & Renal failure, 63 (2.0) & $\begin{array}{l}\text { Disorders of nutrition, } \\
\text { metabolism, and fluid } \\
\text { and electrolytes, } 21 \text { (2.0) }\end{array}$ & & & \\
\hline & Cellulitis, 137 (2.1) & $\begin{array}{c}\text { Esophagitis, } \\
\text { gastroenteritis, and } \\
\text { miscellaneous digestive } \\
\text { disorder, } 57(1.8)\end{array}$ & $\begin{array}{c}\text { Esophagitis, } \\
\text { gastroenteritis, and } \\
\text { miscellaneous digestive } \\
\text { disorder, } 19(1.8)\end{array}$ & & & \\
\hline & $\begin{array}{c}\text { Esophagitis, } \\
\text { gastroenteritis, and } \\
\text { miscellaneous digestive } \\
\text { disorder, } 136(2.0)\end{array}$ & $\begin{array}{l}\text { Alcohol/drug abuse or } \\
\text { dependence, } 56(1.8)\end{array}$ & $\begin{array}{l}\text { Hip and femur procedures } \\
\text { except major joint, } \\
18(1.7)\end{array}$ & & & \\
\hline & $\begin{array}{l}\text { Alcohol/drug abuse or } \\
\text { dependence, } 121(1.8)\end{array}$ & $\begin{array}{l}\text { Hip and femur procedures } \\
\text { except major joint, } \\
56(1.8)\end{array}$ & Diabetes mellitus, 18 (1.7) & & & \\
\hline & $\begin{array}{l}\text { Hip and femur procedures } \\
\text { except major joint, } \\
98(1.5)\end{array}$ & Cellulitis, 49 (1.6) & $\begin{array}{c}\text { Disorder of liver except } \\
\text { malignancy, cirrhosis, } \\
\text { alcoholic hepatitis, } \\
16(1.5)\end{array}$ & & & \\
\hline & $\begin{array}{c}\text { Disorders of pancreas } \\
\text { except malignancy, } 97 \\
(1.5)\end{array}$ & $\begin{array}{l}\text { Heart failure and shock, } \\
47(1.5)\end{array}$ & $\begin{array}{c}\text { Disorders of pancreas } \\
\text { except malignancy, } \\
16(1.5)\end{array}$ & & & \\
\hline
\end{tabular}

Pairwise comparison between specified groups.

${ }^{b}$ Case-mix index is based on the mean Medicare Severity-Diagnosis Related Group weight, reflecting the average resource utilization within a given Diagnosis Related Group applied to inpatient admissions. The number of inpatient admissions used to calculate the case-mix index for each team are as follows: resident team, 6,659 (83.8\%); APC team, 3,088 (87.8\%); and hospitalist team, $1,057(84.3 \%)$.

'Diagnosis based on Medicare Severity-Diagnosis Related Group assigned to admissions with inpatient status. The number of inpatient admissions used to calculate percentages are: resident team, 6,659; APC team, 3,088; and hospitalist team, 1,057.

Abbreviations: APC, advanced practice clinician; IQR, interquartile range; $\mathrm{CCl}$, Charlson Comorbidity Index; OR, operating room. 
TABLE 2. Comparison of Unadjusted Clinical Outcomes and Resource Utilization Among Resident, APC, and Hospitalist Teams

\begin{tabular}{|c|c|c|c|c|c|c|}
\hline & $\begin{array}{l}\text { Resident team } \\
(\mathrm{N}=7,943)\end{array}$ & $\begin{array}{c}\text { APC team } \\
(\mathrm{N}=3,519)\end{array}$ & $\begin{array}{l}\text { Hospitalist team } \\
\qquad(N=1,254)\end{array}$ & $\begin{array}{c}P \text { value }^{\mathrm{a}} \\
\text { (Resident vs APC) }\end{array}$ & $\begin{array}{c}P \text { value }^{\mathrm{a}} \\
\text { (APC vs hospitalist) }\end{array}$ & $\begin{array}{c}P \text { value }^{\mathrm{a}} \\
\text { (Resident vs hospitalist) }^{\text {(Res }}\end{array}$ \\
\hline \multicolumn{7}{|l|}{ Clinical outcomes } \\
\hline $\begin{array}{l}\text { Length of stay in days, } \\
\text { median (IQR) }\end{array}$ & $2.90(1.86,4.26)$ & $2.93(1.89,4.66)$ & $2.86(1.84,4.67)$ & .366 & .062 & .214 \\
\hline 30-day readmissions, No. (\%) & $754(9.5)$ & $311(8.8)$ & $109(8.7)$ & .265 & .876 & .366 \\
\hline In-hospital mortality, №. (\%) & $42(0.5)$ & $24(0.7)$ & $9(0.7)$ & .317 & .896 & .402 \\
\hline \multicolumn{7}{|l|}{ Resource utilization } \\
\hline $\begin{array}{l}\text { Normalized total cost, median } \\
\text { (IQR) }\end{array}$ & $0.92(0.60,1.51)$ & $1.00(0.66,1.60)$ & $0.93(0.61,1.57)$ & $<.001$ & .008 & .540 \\
\hline $\begin{array}{l}\text { Discharge order time } \\
\text { (hours after midnight), median } \\
\text { (IQR) }\end{array}$ & $12.1(10.38,13.90)$ & $11.73(10.00,13.87)$ & $11.20(9.63,13.6)$ & $<.001$ & $<.001$ & $<.001$ \\
\hline $\begin{array}{l}\text { Discharge time } \\
\text { (hours after midnight), median } \\
\text { (IQR) }\end{array}$ & $15.07(13.42,16.73)$ & $14.97(13.23,16.72)$ & $14.53(12.82,16.42)$ & .045 & .002 & $<.001$ \\
\hline $\begin{array}{l}\text { Consults per admission, median } \\
\text { (IQR) }\end{array}$ & $1(0,1)$ & $1(0,2)$ & $1(0,1)$ & $<.001$ & $<.001$ & .088 \\
\hline $\begin{array}{l}\text { aPairwise comparison between } \\
\text { Abbreviations: APC, advanced }\end{array}$ & $\begin{array}{l}\text { ed groups. } \\
\text { e clinician; } I Q R \text {, inte }\end{array}$ & e range. & & & & \\
\hline
\end{tabular}

lieve several findings from our study warrant further discussion.

First, although hospitalist teams were able to discharge patients more efficiently, this observation may be influenced by factors of workflow rather than caused by significant disparities in efficiency between provider types (ie, APC vs hospitalist vs resident physician). As with most academic centers, patients assigned to resident teams are presented by house staff to an attending physician who is ultimately responsible for patient care decisions. Therefore, it is conceivable that delays in the discharge process are in part related to the convention of bedside rounding and discussing the care plan prior to discharge..$^{20}$ In fact, we recognized this as a bottleneck and changed our discharge process for resident teams in June 2017, with a measurable improvement in discharge times. In the absence of this intervention, our observed differences in discharge times among teams may have been even greater.

Second, no significant differences in clinical outcomes were observed in our adjusted analyses, which suggests that a similar quality of care is delivered to patients regardless of team structure, an important observation when considering different staffing models.

Third, we observed a significant increase in consultation use among resident and APC teams, compared with hospitalists. While we are not able to precisely identify the basis for this variation, we believe it could reflect differences in clinical experience, comfort with diagnostic uncertainty, or the unequal distribution of patients transferred from outside hospitals for tertiary care. Interestingly, the greater consultation use did not correlate with higher healthcare costs, a finding recently reported by Stevens et al. ${ }^{21}$
Fourth, we believe the lack of differences in cost and clinical outcomes among team structures may be of particular interest to academic centers when considering physician burnout, salaries, and clinical education. The relationship between clerical burden, such as completing clinical documentation and computerized physician order entry, has been implicated as a risk factor for physician burnout. ${ }^{22}$ Incorporating APCs into roles similar to those performed by resident physicians may reduce the clerical burden on hospitalists, thereby reducing the risk of physician burnout. The addition of APCs may also represent opportunities for cost savings for healthcare centers when comparing the median salary of an APC to that of an internal medicine hospitalist. ${ }^{23,24}$ Moreover, academic hospitalists have been shown to be excellent medical educators and report increased job satisfaction with a variety of duties beyond direct patient care..$^{24,25}$ Unforeseen benefits of adding APC teams within our institution has been the added teaching opportunities for APCs and APC students, increased collegiality with the APCs, and the creation of an APC fellowship program with a focus on inpatient medicine. Similar postgraduate training programs have been reported and serve as effective models to train APCs for hospital-based practice. ${ }^{26}$

Lastly, although this project was conceived and completed prior to the COVID-19 pandemic, our observations may be informative for medical centers experiencing a workforce shortage caused by a surge of COVID-19 patients. During a physician shortage we believe our APC team model could be rapidly expanded to accommodate a large influx of patients. This expansion could be accomplished through a single attending phy- 
TABLE 3. Comparison of Adjusted Clinical Outcomes and Resource Utilization Among Resident, APC, and Hospitalist Teams $^{*}$

\begin{tabular}{|c|c|c|c|c|c|c|}
\hline & $\begin{array}{l}\text { Resident team } \\
(\mathrm{N}=7,943)\end{array}$ & $\begin{array}{l}\text { APC team } \\
(\mathrm{N}=3,519)\end{array}$ & $\begin{array}{l}\text { Hospitalist team } \\
\qquad(\mathrm{N}=1,254)\end{array}$ & $\begin{array}{c}P_{\text {value }} \\
\text { (Resident vs APC) }\end{array}$ & $\begin{array}{c}P \text { value }^{\mathrm{a}} \\
\text { (APC vs hospitalist) }\end{array}$ & $\begin{array}{c}P \text { value }^{\mathrm{a}} \\
\text { (Resident vs hospitalist) }^{\text {(Ros }}\end{array}$ \\
\hline \multicolumn{7}{|l|}{ Clinical outcomes } \\
\hline $\begin{array}{l}\text { Length of stay in days, mean } \\
(95 \% \mathrm{Cl})\end{array}$ & $3.54(3.48-3.59)$ & $3.60(3.51-3.69)$ & $3.57(3.42-3.73)$ & .233 & .754 & .643 \\
\hline $\begin{array}{l}\text { 30-day readmissions, OR } \\
(95 \% \mathrm{Cl})\end{array}$ & $1.07(0.93-1.23)$ & $1.01(0.80-1.27)$ & $0.93(0.75-1.15)$ & .355 & .935 & .501 \\
\hline $\begin{array}{l}\text { In-hospital mortality, OR } \\
(95 \% \mathrm{Cl})\end{array}$ & $0.87(0.52-1.45)$ & $0.93(0.43-2.02)$ & $1.21(0.58-2.53)$ & .587 & .857 & .604 \\
\hline \multicolumn{7}{|l|}{ Resource utilization } \\
\hline $\begin{array}{l}\text { Normalized total cost, mean } \\
(95 \% \mathrm{Cl})\end{array}$ & $0.97(0.95-0.99)$ & $1.00(0.97-1.03)$ & $0.98(0.94-1.04)$ & .172 & .463 & .901 \\
\hline $\begin{array}{l}\text { Discharge order time } \\
\text { (hours after midnight), mean } \\
(95 \% \mathrm{Cl})\end{array}$ & $12.16(12.11-12.22)$ & $11.95(11.87-12.03)$ & $11.62(11.49-11.76)$ & $<.001$ & $<.001$ & $<.001$ \\
\hline $\begin{array}{l}\text { Discharge time } \\
\text { (hours after midnight), mean } \\
(95 \% \mathrm{Cl})\end{array}$ & $15.02(14.97-15.08)$ & $14.89(14.80-14.98)$ & $14.58(14.44-14.72)$ & .015 & $<.001$ & $<.001$ \\
\hline $\begin{array}{l}\text { Consults per admission, mean } \\
(95 \% \mathrm{Cl})\end{array}$ & $0.93(0.90-0.95)$ & $1(0.96-1.03)$ & $0.85(0.80-0.90)$ & .001 & $<.001$ & .013 \\
\hline $\begin{array}{l}\text { *Outcomes adjusted for age, } \\
\text { aPairwise comparison betweer } \\
\text { Abbreviations: APC, advancec }\end{array}$ & $\begin{array}{l}\text { der, Charlson Comorbic } \\
\text { ecified groups. } \\
\text { ctice clinician; OR, odd }\end{array}$ & ndex, transfer from ou & hospital, and nighttim & mission. & & \\
\hline
\end{tabular}

sician overseeing multiple APC teams. In this model, the supervising physician would only evaluate the most complex patients with most patients being managed solely by an APC from admission to discharge. Such changes may require temporary suspension of state laws restricting APC independent practice..$^{27,28}$

Our findings contrast those of previous reports in that we did not observe significant differences in clinical outcomes (ie, LOS, inpatient mortality, and 30-day readmissions) or total direct cost. ${ }^{8,10,21}$ Other institutions have noted an increased LOS among APC teams and hospitalist teams, compared with resident teams. ${ }^{8,10}$ Furthermore, Chin et al and lannuzzi et al reported reductions in healthcare cost for resident teams, whereas our study did not identify significant cost differences among team structures. Although we cannot pinpoint the exact reason(s) for these dissimilarities, it is plausible that unmeasured factors such as institutional differences in APC training, direct physician supervision, admission processes, or inpatient team census may play a role.

Several study limitations should be recognized. First, the retrospective, nonrandomized design is one of the largest limitations of our study. Administrative data was obtained via an electronic query of our data warehouse, and although we aimed to identify as many patient characteristics as possible to adjust for cofounding effects, undetected differences among cohorts may exist. Second, our inpatient admission process may have placed undue burden on resident teams to perform all daytime admissions, inadvertently affecting study outcomes. It is possible the observed benefits of a solo hospitalist team are attributable to the lack of admitting duties rather than inherent advantages of the team structure. If this were the case, we would expect similar benefits among APC teams, which we did not note. Third, the study was performed at a single academic center, which may limit the generalizability of our results. Fourth, it is possible the outcomes are similar among teams because our hospitalist faculty rotate proportionately between the different teams. Lastly, the study was underpowered to detect a significant difference in mortality between hospitalist and APC teams. A post hoc power calculation based on our observed sample and effect sizes estimated $75 \%$ power to detect a mortality difference between hospitalists and APCs; other mortality comparisons were adequately powered.

\section{CONCLUSION}

We observed similar total direct costs, LOS, 30-day readmission, and inpatient mortality between hospitalist, APC, and resident teams. APC and resident teams utilized more consultants and discharged patient later than hospitalists. Our analysis suggests clinical outcomes are not significantly affected by inpatient team structure, and the addition of general medicine inpatient APC or hospitalist teams represent safe and efficient alternatives to traditional resident teams within an academic medical center.

Disclosures: All authors declare they have no conflicts of interest. 


\section{References}

1. Report of the Work Group on Resident Duty Hours and the Learning Environ ment, June 11, 2002. Accreditation Council for Graduate Medical Education; 2003

2. ACGME Task Force on Quality Care and Professionalism. Philibert I, Amis Steve, eds. The ACGME 2011 Duty Hour Standards: Enhancing Quality of Care, Supervision, and Resident Professional Development. Accreditation Council for Graduate Medical Education; 2011. https://www.acgme.org/Portals/0/PDFs/jgme-monograph[1].pdf

3. Konstam MA, Hill JA, Kovacs RJ, et al. The academic medical system: reinvention to survive the revolution in health care. J Am Coll Cardiol. 2017;69(10):1305-1312. https://doi.org/10.1016/j.jacc.2016.12.024

4. The future of the academic medical center: strategies to avoid a margin meltdown. Health Research Institute. February 2012. https://uofuhealth.utah. edu/hcr/2012/resources/the-future-of-academic-medical-centers.pdf

5. Moote M, Krsek C, Kleinpell R, Todd B. Physician assistant and nurse practitioner utilization in academic medical centers. Am J Med Qual. 2019;34(5):465-472. https://doi.org/ 10.1177/1062860619873216

6. Roy $\mathrm{CL}$, Liang $\mathrm{CL}$, Lund $\mathrm{M}$, et al. Implementation of a physician assistant/ hospitalist service in an academic medical center: impact on efficiency and patient outcomes. J Hosp Med. 2008;3(5):361-368. https://doi.org/10.1002/ jhm.352

7. Denne E. Behind the scenes at Northwell Health as PAs respond to COVID-19. American Academy of Physician Assistants. May 11, 2020. Accessed May 15, 2020. https://www.aapa.org/news-central/2020/05/behindthe-scenes-at-northwell-heath-as-pas-respond-to-covid-19/

8. Chin DL, Wilson MH, Bang H, Romano PS. Comparing patient outcomes of academician-preceptors, hospitalist-preceptors, and hospitalists on internal medicine services in an academic medical center. J Gen Intern Med. 2014;29(12):1672-1678. https://doi.org/10.1007/s11606-014-2982-y

9. Cowan MJ, Shapiro M, Hays RD, et al. The effect of a multidisciplinary hospitalist/physician and advanced practice nurse collaboration on hospital costs J Nurs Adm. 2006;36(2):79-85. https://doi.org/10.1097/00005110-20060200000006

10. Iannuzzi MC, lannuzzi JC, Holtsbery A, Wright SM, Knohl SJ. Comparing hospitalist-resident to hospitalist-midlevel practitioner team performance on length of stay and direct patient care cost. J Grad Med Educ. 2015;7(1):65-69. https://doi.org/10.4300/jgme-d-14-00234.1

11. Kapu AN, Kleinpell R, Pilon B. Quality and financial impact of adding nurse practitioners to inpatient care teams. J Nurs Adm. 2014;44(2):87-96. https:// doi.org/10.1097/nna.0000000000000031

12. Singh S, Fletcher KE, Schapira MM, et al. A comparison of outcomes of general medical inpatient care provided by a hospitalist-physician assistant model vs a traditional resident-based model. J Hosp Med. 2011;6(3):122-130. https://doi.org/10.1002/jhm.826

13. Timmermans MJC, van Vught A, Peters YAS, et al. The impact of the implementation of physician assistants in inpatient care: a multicenter matched-controlled study. PLoS One. 2017;12(8):e0178212. https://doi. org/10.1371/journal.pone.0178212
14. Timmermans MJC, van den Brink GT, van Vught A, et al. The involvement of physician assistants in inpatient care in hospitals in the Netherlands: a cost-effectiveness analysis. BMJ Open. 2017;7(7):e016405. https://doi. org/10.1136/bmjopen-2017-016405

15. Charlson ME, Pompei P, Ales KL, MacKenzie CR. A new method of classifying prognostic comorbidity in longitudinal studies: development and validation. J Chronic Dis. 1987;40(5):373-383. https://doi.org/10.1016/00219681(87)90171-8

16. MS-DRG Classifications and Software. Centers for Medicare \& Medicaid Services. 2020. Updated April 28, 2020. Accessed May 5, 2020. https://www. cms.gov/Medicare/Medicare-Fee-for-Service-Payment/AcutelnpatientPPS/ MS-DRG-Classifications-and-Software

17. Fetter RB, Shin Y, Freeman JL, Averill RF, Thompson JD. Case mix definition by diagnosis-related groups. Med Care. 1980;18(2 Suppl):iii, 1-53.

18. Nichani S, Crocker J, Fitterman N, Lukela M. Updating the core competencies in hospital medicine--2017 revision: introduction and methodology. $J$ Hosp Med. 2017;12(4):283-287. https://doi.org/10.12788/jhm.2715

19. Williams R. Using the margins command to estimate and interpret adjusted predictions and marginal effects. Stata J. 2012;12(2):308-331. https://doi.org/ 10.1177\%2F1536867X1201200209

20. Goolsarran N, Olowo G, Ling Y, Abbasi S, Taub E, Teressa G. Outcomes of a resident-led early hospital discharge intervention. J Gen Intern Med. 2020;35(2):437-443. https://doi.org/10.1007/s11606-019-05563-w

21. Stevens JP, Hatfield LA, Nyweide DJ, Landon B. Association of variation in consultant use among hospitalist physicians with outcomes among Medicare beneficiaries. JAMA Netw Open. 2020;3(2):e1921750. https://doi. org/10.1001/jamanetworkopen.2019.21750

22. Shanafelt TD, Dyrbye LN, Sinsky C, et al. Relationship between clerical burden and characteristics of the electronic environment with physician burnout and professional satisfaction. Mayo Clin Proc. 2016;91(7):836-848. https://doi. org/10.1016/j.mayocp.2016.05.007

23. 2019 AAPA Salary Report. American Academy of PAs. 2019. https://www. aapa.org/shop/salary-report-2019/

24. Hinami K, Whelan CT, Miller JA, Wolosin RJ, Wetterneck TB; Society of Hospital Medicine Career Satisfaction Task Force. Job characteristics, satisfaction, and burnout across hospitalist practice models. J Hosp Med. 2012;7(5):402-410. https://doi.org/10.1002/jhm.1907

25. Dalen JE, Ryan KJ, Waterbrook AL, Alpert JS. Hospitalists, medical education, and US health care costs. Am J Med. 2018;131(11):1267-1269. https:// doi.org/10.1016/j.amjmed.2018.05.016

26. Will KK, Budavari Al, Wilkens JA, Mishark K, Hartsell ZC. A hospitalist postgraduate training program for physician assistants. J Hosp Med. 2010;5(2):9498. https://doi.org/10.1002/jhm.619

27. Utah Physician Assistant Act. Utah Code. Published 2019. Accessed May 8, 2020. https://le.utah.gov/xcode/Title58/Chapter70A/C5870a_2019051420190514.pdf

28. Nurse Practice Act. Utah Code. Published 2019. Accessed May 8, 2020. https:// le.utah.gov/xcode/Title58/Chapter31B/C58-31b_1800010118000101.pdf 